\title{
Granuloma Multiforme: First Report from Nepal
}

\author{
Paudel S ${ }^{1}$, Marahatta S $^{2}$
}

${ }^{1}$ Department of Dermatology, ${ }^{2}$ Department of Pathology, Civil Servive Hospital, Kathmandu.

\begin{abstract}
Granuloma multiforme (GM) is a reactive skin disorder of unknown etiology, characterized clinically by confluent annular lesions and histologically by focal necrobiosis and histiocytic granulomas. GM is significant because it mimics various conditions and diagnosis is often missed if not taken into consideration. Here, we report a case of granuloma multiforme from Nepal in a 40 year old female with multiple skin colored to mildly erythematous, occasionally itchy annular plaques of duration 6 months, over the upper back and upper chest. Histopathology helped to clinch the diagnosis and differentiate from similar clinical and histologic mimics.
\end{abstract}

Key words: Granuloma; Necrobiotic disorders; Nepal; Skin

\section{Introduction}

$T$ he term Granuloma Multiforme (GM) was coined in 1964 by Leiker et al, ${ }^{1}$ to describe a reactive skin disorder of unknown etiology which resembled leprosy but had different histology. GM is a chronic granulomatous skin condition, characterized clinically by firm papules aggregated into plaques or forming the edges of annular lesions, and histologically by focal necrobiosis and histiocytic granulomas ${ }^{2}$. Many such cases were, then, observed in Africa ${ }^{1,3-8}$ and India. ${ }^{2,9-12}$ This is the first case report from Nepal.

\section{Case report}

A 40 year old female from Kathmandu presented with multiple occasionally itchy, ring-shaped lesions gradually increasing in number since 6 months over her upper back and upper chest. These lesions started as itchy papules from the upper back region and gradually enlarged and covered new sites. She was a housemaid and frequently worked outdoor.

On examination, there were multiple annular and polycyclic plaques with raised beaded borders distributed asymmetrically over the upper back and upper chest with central clearing without skin changes, along with a few discrete papules. The plaques ranged

\section{Address of Correspondence}

Dr. Sushil Paudel, MD

Registrar

Department of Dermatology

Civil service Hospital, Kathmandu

E-mail: paudelsushil@gmail.com from 2 to $6 \mathrm{~cm}$ in diameter (Figures 1,2). The border was soft to firm in consistency. There was no loss of sensation over the lesions and no peripheral nerve thickening. Systemic examination was normal.

Clinical possibilities considered were granuloma annulare, actinic granuloma, annular sarcoid and granuloma multiforme. Routine lab investigations and Chest $\mathrm{X}$ ray were all normal.

A skin biopsy was taken from the elevated edge of the plaque over upper back and sent for histopathology examination. Histopathology showed perivasular lympho-histiocytic infiltration in the mid dermis along with many multinucleated giant cells, surrounding the disintegrated collagen at the center. No acid-fast bacilli (AFB) were detected. These findings were consistent with a diagnosis of granuloma multiforme. (Figures $3,4)$

Submitted: $15^{\text {th }}$ December 2018

Accepted: $15^{\text {th }}$ February 2019

Published: $31^{\text {st }}$ March 2019

How to cite this article

Paudel S, Marahatta S. Granuloma multiforme: First report from Nepal. Nepal Journal of Dermatology Venereology and Leprology. 2019;17(1):66-8. doi: http://dx.doi.org/10.3126/ njdvl.v17i1.23292

\section{(c) (i)}

Licensed under CC BY 4.0 International License which permits use, distribution and reproduction in any medium, provided the original work is properly cited. 
The patient was followed up for three months advised with strict photoprotection and intermittent topical steroid use which reduced patient's itching but no improvement on the appearance of the skin lesions. However the number of skin lesions did not increase.

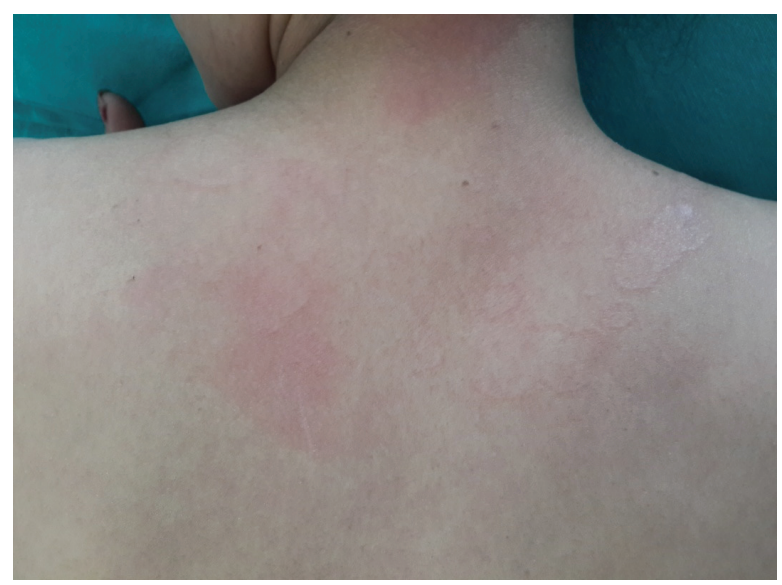

Figure 1: Annular plaques on upper back

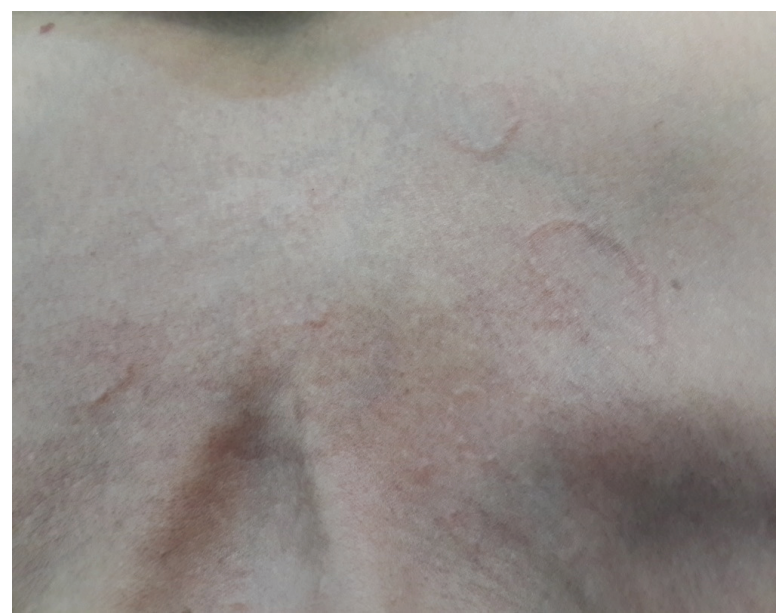

Figure 2: Annular plaques on the chest

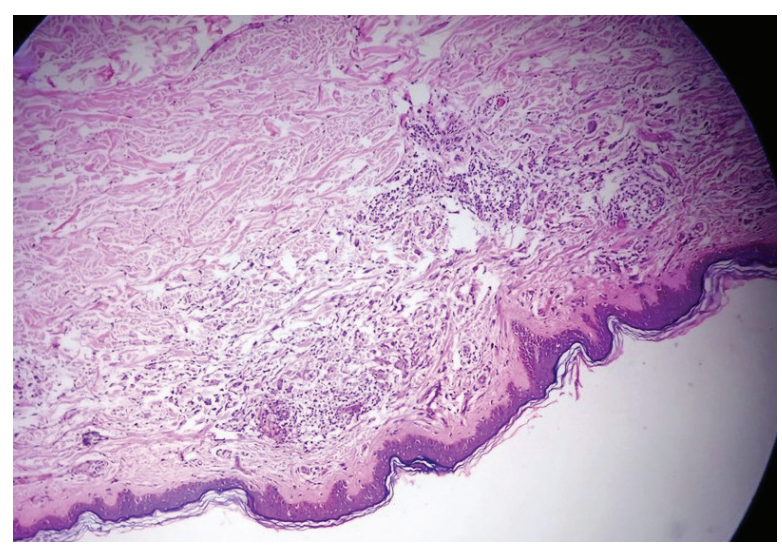

Figure 3: H\&E stain. Granulomatous infiltrates at the mid dermis. $10 \mathrm{X}$

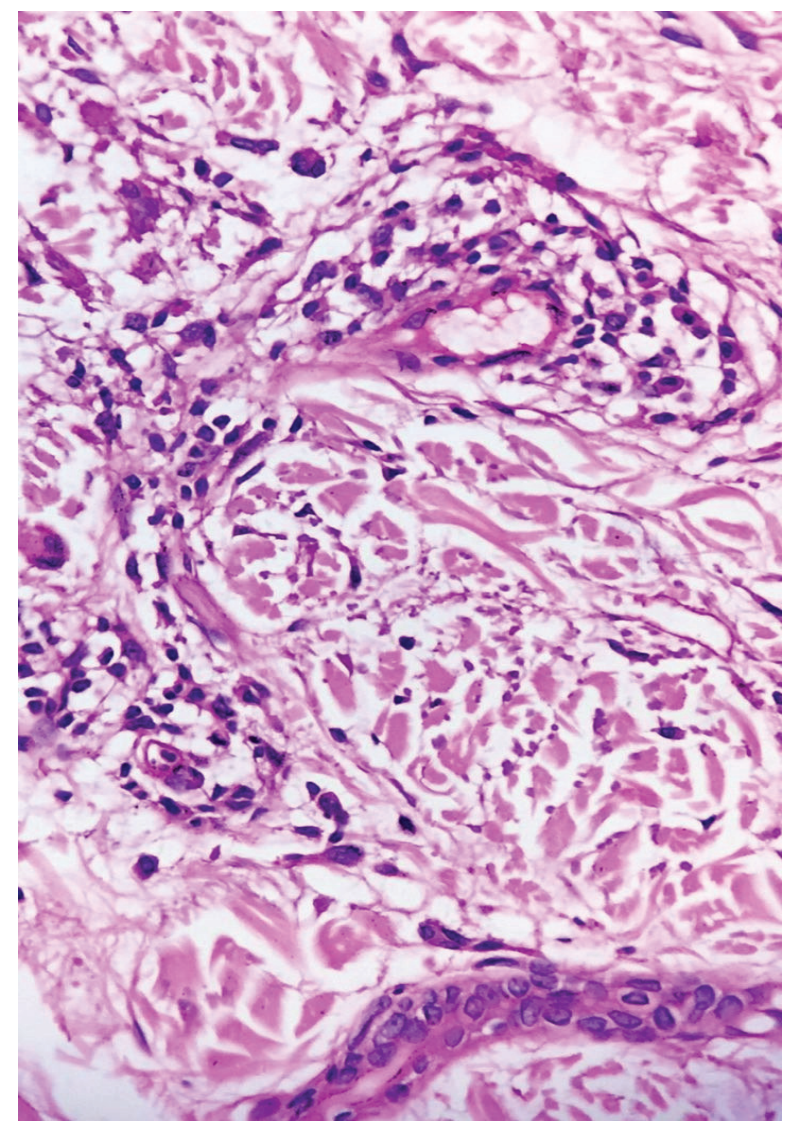

Figure 4: H\&E stain. Perivascular Lympho-histiocytic infiltration along with many giant cells, surrounding central collagen disintegration. 100X

\section{Discussion}

Leiker et $\mathrm{al}^{1}$ was the first to describe this condition as a separate entity from the leprosy in the year 1964 . Since then many cases have been reported mainly from the Africa and India.

The disease is found among adults over the age of 40 years, with a predilection for the female sex. ${ }^{2}$ Cumulative photo damage to the dermal collagen has been favored as the primary pathogenic event of granuloma multiforme. ${ }^{10}$ Favoring this hypothesis is the occurrence of all reported lesions in the photo exposed parts, including our case.

The initial lesions are usually papules, which soon evolve to form annular and polycyclic plaques, which last for months to years. When new lesions are developing itching or irritation is common. ${ }^{2}$ Our case also had itching as a prominent symptom.

Granuloma multiforme has to be distinctly differentiated clinically and histologically from granuloma annulare, actinic granuloma, annular sarcoidosis, and tuberculoid leprosy. 
Granuloma Annulare (GA) are mostly seen in the distal parts of the limbs as smaller rings in younger patients. Histologically it is characterized by mucin deposition in the dermis and giant cells less prominent. ${ }^{2}$

Annular elastolytic giant cell granuloma or actinic granuloma is very similar in clinical presentation with GM. Histologically necrobiosis is usually not seen in actinic granuloma, although all other features are similar. Many authors believe that these two conditions are similar. $^{2}$

Annular sarcoid is easily differentiated by the pathologists by the presence of naked granulomas however clinical differentiation is difficult.

Tuberculoid leprosy lesions are limited in number, have sensory loss, neural thickening and histopathology has typical granulomas in all layers of dermis, neural infiltrates with mononuclear cells with occasional acid

\section{References}

1. Leiker DL, Kok SH, Spaas JAJ. Granuloma multiforme: A new disease resembling leprosy. Int J Lepr. 1964;32:368-76.

2. Kumari R, Thappa DM, Chougule A, Adityan B. Granuloma multiforme: A report from India. Indian J Dermatol Venereol Leprol. 2009;75:2969.https://doi.org/10.4103/0378-6323.51259

3. Marshall J, Weber HW, Kok SH. Granuloma multiforme(Leiker).Dermatologica.1967;134:193207.https://doi.org/10.1159/000254295

4. Leiker DL, Ziedses des Plantes M. Granuloma multiforme in Kenya. East Afr Med J. 1967;44:42936.

5. Browne SG. Granuloma multiforme in Eastern Nigeria. Int J Lepr. 1966;34:27-9.

6. Meyers WM, Connor DH, Shannon R. Histologic characteristics of granuloma multiforme (Mkar disease). Including a comparison with leprosy and fast bacilli within the nerve on FiteFaraco staining and the absence of collagen degeneration. ${ }^{2}$

The etiopathogenesis of GM is still unknown. The cumulative photo damage of the collagen in the presence of (or interplay of) chemical, biological and immunological factors could be the cause of this difficult to treat condition. ${ }^{10}$

Unfortunately, no effective therapy is available for this disorder. Further clinico-pathological studies may shed some light to its pathogenesis and eventual treatment.

\section{Conclusion}

There is a huge paucity of data regarding this condition in Nepalese population; probably it is due to its omission in differential diagnosis. Dermatologists should keep this as one of the differential diagnoses of annular granulomatous disorders.

granuloma annulare. Report of first case from Congo (Kinshasa). Int J Lepr .1970;38:241-9.

7. Huskinson RA. Observations on granuloma multiforme in Uganda. Lepr Rev. 1988;59:270-1.

8. Leiker DL. Distribution of granuloma multiforme. Int J Lepr. Other Mycobact Dis 1971;39:189.

9. Cherian S. Granuloma multiforme in India. Int J Lepr Other Mycobact Dis. 1990;58:719-21.

10. Cherian S. Is granuloma multiforme a photodermatosis? Int J Dermatol. 1994;33:212. https://doi.org/10.1111/j.1365-4362.1994. tb01486.x

11. Sandhu K, Saraswat A, Gupta S, Shukla R, Handa S. Granuloma multiforme. Int J Dermatol. 2004;43:441-3. https://doi.org/10.1111/j.13654632.2004.01979.x

12. Sharma YK, Ankadavar NS, Malik G, Patel RJ. A Rare Report Of Granuloma Multiforme. Indian J Dermatol. 2016 Jan-Feb;61(1):124.https://doi. org/10.4103/0019-5154.174168. 